\title{
Stigma and discrimination in the view of people living with human immunodeficiency virus in Isfahan, Iran
}

\author{
Setayesh Sindarreh ${ }^{1}$, Fatemeh Ebrahimi ${ }^{1}$, Maryam Nasirian ${ }^{1,2}$ \\ ${ }^{1}$ Department of Epidemiology and Biostatistics, Health School, and Infectious Diseases and Tropical Medicine Research Center, \\ Isfahan University of Medical Sciences, Isfahan, Iran \\ ${ }^{2}$ HIV/STI Surveillance Research Center, and WHO Collaborating Center for HIV Surveillance, Institute for Futures Studies \\ in Health, Kerman University of Medical Sciences, Kerman, Iran
}

\begin{abstract}
Introduction: In Iran, human immunodeficiency virus (HIV) is a stigmatized issue and there is a negative attitude towards the disease. The stigma and discrimination because of HIV can affect both physical and mental health, social activities, and the quality of life of HIV-positive people. The aim of this study was to evaluate the attitude towards HIV infection among people living with HIV (PLHIV) in Isfahan, Iran.

Material and methods: This cross-sectional study examined $99 \mathrm{HIV}$-positive patients from the Isfahan Health Center, Isfahan, Iran, in December 2017. A standard questionnaire through a cross-sectional study was used to evaluate the attitude concerning HIV infection among PLHIV. In addition, linear regression was used to assess factors affecting attitude among PLHIV.

Results: About $24 \%$ of participants had good levels of attitude, whereas $67.71 \%$ of them had a moderate attitude. In addition, around $93 \%$ of respondents believed that to allow PLHIV to joint freely in all social activities. The evaluated factors such as gender $(p=0.28)$, age $(p=0.96)$, educational level $(p=0.83)$, and marital status and occupation $(p=0.58)$, did not have a significant relationship with the attitude score.

Conclusions: The attitude to HIV infection was not satisfactory among PLHIV in Isfahan, considering that HIV/AIDS-related stigma can cause personal, familial, and social problems. Therefore, appropriate actions are needed to improve the attitude and to reduce stigma associated with HIV infection.
\end{abstract}

HIV AIDS Rev 2020; 19, 2: 132-138

DOI: https://doi.org/10.5114/hivar.2020.96489

Key words: HIV, AIDS, stigma, attitude, Iran.

\section{Introduction}

In the current century, acquired immune deficiency syndrome (AIDS) is a major health problem that has become a pandemic threat to the world $[1,2]$. In Iran, the first case of this disease was reported in 1986 (a boy with hemophilia) [3]. Together with most countries in Asia, the number of AIDS cases in Iran has risen rapidly $[1,2,4]$. Based on the report of human immunodeficiency virus (HIV)/AIDS surveillance system in Iran, about 36,600 HIV-infected people have been identified by the end of December 2017 [5]. In Iran, the most dominant route of HIV transmission was injection drug use, while in recent years, sexual contact has been identified as main way of HIV acquisition $[3,6]$. Due to the current situation in Iran, including high incidence of drug abuse [7] and frequent exchange of needles among injecting
Address for correspondence: Dr. Maryam Nasirian, Department of Epidemiology and Biostatistics, Health School, and Infectious Diseases and Tropical Medicine Research Center, Isfahan University of Medical Sciences, Isfahan, Iran, e-mail: maryamnasirian17@gmail.com
Article history:

Received: 15.01.2019

Received in revised form: 06.06.2019

Accepted: 17.07.2019

Available online: 19.06 .2020
International Journal of HIV-Related Problems

HIV \& AIDS

R e v i e w 
drug users [8], high percentage of youth in the country [9], increasing marriage age [10], increased divorce rate [11], growing number of sexually transmitted diseases and defects in sexual health knowledge [12], if the necessary prevention programs are not taken, AIDS can spread rapidly in Iran [12]. Therefore, according to the above, planning to prevent and control HIV in Iran must be of highest importance. The stigma and discrimination towards HIV are the main barriers of successful HIV controlling [13]. Since the first diagnosis, HIV and AIDS have been associated with stigma, discrimination, and fear because in the early years of the advent of this disease, gay men who had extramarital sex $[14,15]$ have been reported. Stigma, as a negative attitude of the society towards people living with HIV (PLHIV) results in fear of discrimination or experience of discrimination $[6,16]$. PLHIV may experience unfavorable conditions related to stigma such as social rejection, discrimination, shame, abuse, general fear of disease, delivery of poor quality healthcare, and separation in hospital sector $[6,13,17]$. Several studies have shown that stigma has a significant impact on some health behaviors such as unwillingness to carry out HIV testing and voluntary counseling, failure to maintain medical regimens, and non-disclosure of HIV infection status to others [17-20]. As a result, stigma leads to spreading of the HIV/AIDS epidemic [18]. Consistent with other countries $[15,19,21]$, AIDS in Iran is a highly stigmatized issue, with negative attitude of the society towards the disease [6]. The study by Karamouzian et al. in 2015 indicated that PLHIV are exposed to stigma and discrimination from families, communities, and healthcare systems [4]. Therefore, considering that stigma can affect both physical and mental health, social activities and, consequently, the quality of life of people with AIDS $[6,15]$, the purpose of this study was to evaluate the attitude of PLHIV towards HIV infection in Isfahan, Iran. Since only one similar study was conducted in Iran [4], this research could act as a pilot study, and we hope it will encourage other authors in Iran to consider this subject.

\section{Material and methods}

This is a cross-sectional study that was approved by the Research Review board of the Isfahan University of Medical Sciences, with IRB code of 196015 . HIV attitude among PLHIV in Isfahan was evaluated in December 2017.

\section{Sample size and sampling}

Due to low number of PLHIV in Isfahan city, we used the census method instead of sampling. Finally, 99 eligible participants were selected.

\section{Data collection}

In order to collect the data, a health worker was trained who was associated and familiar with participants. After providing a brief explanation of study objectives, interviewing method and confidentiality of information was provided by the interviewer and verbal informed consents from all participants were obtained. Then, the interviewer asked them questions and inserted the answers in the questionnaire.

The survey instrument was a part of a standard questionnaire, which was designed and standardized by Tavakoli [22]. The Cronbach a coefficient for attitude towards HIV/AIDS in the current sample was 0.74 . The questionnaire consisted of 5 items on demographic characteristics and 18 items on attitude. Items on the attitude included 5 items on patient's social status, 4 items on social support, 7 items on social understanding of the disease, and 2 items on social harassment domain. Questions were designed based on Likert scale with 5 options (strongly disagree, disagree, no idea, agree, and strongly agree), meaning that if strongly disagree to strongly agree, scores were 1 to 5 , and in the opposite questions, if strongly disagree to strongly agree, scores were 5 to 1 . The total score of attitudes was determined by collecting the scores of attitude questions (18-90). To rate the attitude score, we used statistical quartiles, which were already used in other paper [15]. The poor attitude group included those individuals with score lower than or equal to the value of second quartile or median $(\leq 54)$; for a moderate attitude, we considered the ranging from second quartile to third quartile (55-72), while the high attitude group included those who scored greater than the third quartile, ranging from 73-90, the attitude score variable.

\section{Statistical analysis}

Following data collection, questionnaires were checked, and their deficiencies resolved before coding. Then, the results were entered into State v. 14 software. Data entry errors were checked, and missing data were corrected by referring to the questioner and request the missing data from PLHIV.

Descriptive statistics including mean, standard deviation, and frequency were used to describe the results. Variables were compared in male and female by $\chi^{2}$ and $t$-test. Linear regression was conducted to assess factors affecting the attitude among PLHIV. All $p$-values were two-sided, and a significant level of less than $5 \%$ were considered for all analysis.

\section{Ethical consideration}

Given the sensitivity of the subject, a written informed consent was not feasible. Therefore, after explaining the purpose of the study, and ensuring the confidentiality of information and independence of individuals in participating in the study, verbal informed consent was obtained from all participants.

\section{Results}

\section{Demographic information}

As shown in Table 1, a total of 99 (36.36\% men) respondents aged 18-71 years old were enrolled. The mean (SD) age was 40.74 (10.46) years. More than half of participants 
Table 1. Demographic characteristics of participants

\begin{tabular}{|c|c|c|c|}
\hline Parameter & $\begin{array}{c}\text { Men } \\
(n=36)\end{array}$ & $\begin{array}{l}\text { Women } \\
(n=63)\end{array}$ & $p$-value* \\
\hline $\begin{array}{l}\text { Age }(\text { mean } \pm S D) \\
\text { (years) }\end{array}$ & $\begin{array}{c}37.80 \\
\pm 10.48\end{array}$ & $\begin{array}{c}42.42 \\
\pm 10.15\end{array}$ & 0.03 \\
\hline \multicolumn{4}{|l|}{ Marital status (\%) } \\
\hline Single & $4(11.43)$ & $27(42.86)$ & \multirow[t]{4}{*}{0.002} \\
\hline Married & $21(60.00)$ & $30(47.62)$ & \\
\hline Divorced & $5(14.29)$ & $5(7.94)$ & \\
\hline Widow & $5(14.29)$ & $1(1.59)$ & \\
\hline \multicolumn{4}{|l|}{ Educational level (\%) } \\
\hline Illiterate & $2(5.56)$ & $4(6.35)$ & \multirow[t]{3}{*}{0.960} \\
\hline $\begin{array}{l}\text { Incomplete/ } \\
\text { Complete high } \\
\text { school }\end{array}$ & $30(83.33)$ & $53(84.13)$ & \\
\hline Graduated & $4(11.11)$ & $6(9.52)$ & \\
\hline \multicolumn{4}{|l|}{ Occupation (\%) } \\
\hline Healthy worker & 0 & 0 & \multirow[t]{6}{*}{$<0.0001$} \\
\hline $\begin{array}{l}\text { Government's } \\
\text { employee }\end{array}$ & $2(5.88)$ & $2(3.23)$ & \\
\hline Homemaker & $4(11.76)$ & $24(38.71)$ & \\
\hline Student & $20(58.82)$ & 0 & \\
\hline Other & $1(2.94)$ & 0 & \\
\hline Unemployed & $7(20.59)$ & $36(58.06)$ & \\
\hline
\end{tabular}

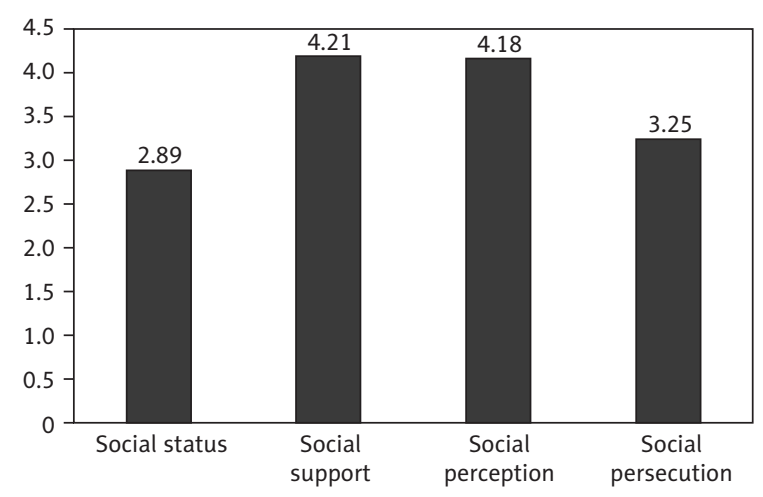

Figure 1 . The results of attitude scale with mean of the four subscales

had incomplete/complete high school educations (83.84\%) and about $52.4 \%$ of them were married. Also, $44.33 \%$ of participants were unemployed. In addition, as can be seen in Table 1, there was a significant difference in terms of age, marital status, and occupational position in males and females.

\section{Attitude toward people living with HIV}

Results showed that mean (SD) score of HIV attitude was $3.72(0.43)$. A total of $23.96 \%, 67.71 \%$, and $8.33 \%$ of the re- spondents presented good (range, 73-90), moderate (range, 55-72), and poor (range, 18-54) levels of HIV attitude, respectively. Mean (SD) score of attitudes among women was 3.68 (0.42) and among men was 3.78 (0.43). However, no significant difference between them was noted $(p=0.28)$. More than $40 \%$ of participants agreed that PLHIV would be embarrassed by themselves and their families. In addition, around $93 \%$ of respondents believed to allow PLHIV to joint freely in all social activities. Also, $82.29 \%$ of them strongly agreed that PLHIV should receive healthcare and treatment similar to other patients. Respondents strongly opposed that PLHIV are sinful (60\%). Moreover, the participants believed that PLHIV should not be punished due to their disease (73.6\%). About $43 \%$ and $17.52 \%$ of participants stated that PLHIV are abused verbally and physically, respectively. Finally, $31.6 \%$ of respondents specified that HIV infection is a consequence of wrong past behaviors (Table 2).

As showed in Table 3, in social support scope, age ( $p=0.038$ ) was associated with score of attitudes, but this association was not found in another domain.

The results of attitude scale with mean of the four subscales are shown in Figure 1. The mean scores for the four subscales were patient's social status $(2.89 \pm 0.97)$, social support $(4.21 \pm 0.71)$, social understanding of the disease (4.18 \pm 0.62$)$, and social harassment $(3.25 \pm 1.05)$.

\section{Discussion}

The result of this data analysis from a cross-sectional study of PLHIV aged 18-71 years showed that the overall attitude score of patients on HIV was on moderate level. In addition, the attitude scores were evaluated in four subscales including patient's social status, social support, social understanding of the disease, and social harassment. The mean scores of attitudes in the patients' social status and social harassment were estimated on moderate level, while in the social support and social understanding of the disease, the mean of attitude scores was on good level.

In our study, we found that more than half of the participants had moderate level of attitude towards HIV infection, which is consistent with a literature from other countries. A study conducted in China reported a moderate level of HIV-related stigma among HIV-infected individuals [23]. In addition, Baugher et al. described an average stigma score of 2.4 among HIV-infected adults in the US [24]. The present study is in line with some other studies from Iran. A study by Hedayati-Moghaddam was conducted to assess people's attitudes towards PLHIV in Mashhad, and showed that attitudes were not satisfied [12]. A systematic review evaluated 62 eligible studies published between 1978 and 1987 in Iran. Among those, in 16 eligible studies on attitude (including 11,104 individuals), the reported mean score varied between 32.6 and 78.4, with an overall mean attitude score of 68 (on a scale of 100), which is on moderate level of attitude towards HIV infection [25]. Given that HIV/AIDSrelated stigma has an impact on health and quality of life of PLHIV [13, 20, 26], it seems that moderate level of atti- 
Table 2. Attitude toward people living with HIV

\begin{tabular}{|c|c|c|c|c|c|}
\hline Statements (response for positive attitude) & $\begin{array}{c}\text { Strongly } \\
\text { adverse, } \\
n(\%)\end{array}$ & $\begin{array}{c}\text { Adverse, } \\
n(\%)\end{array}$ & $\begin{array}{c}\text { No idea, } \\
n(\%)\end{array}$ & $\begin{array}{l}\text { Agree, } \\
n(\%)\end{array}$ & $\begin{array}{c}\text { Strongly } \\
\text { agree, } \\
n(\%)\end{array}$ \\
\hline \multicolumn{6}{|l|}{ Patient's social status } \\
\hline Having AIDS can cause the patient's embarrassment ${ }^{a}$ & $17(17.17)$ & $19(19.19)$ & $11(11.11)$ & $42(42.42)$ & $10(10.10)$ \\
\hline $\mathrm{PLWA}^{\&}$ causes his family to be embarrassed & $11(11.11)$ & $22(22.22)$ & $9(9.09)$ & $41(41.41)$ & $16(16.16)$ \\
\hline In our society, PLWA are abandoned by their family ${ }^{a}$ & $22(22.22)$ & $28(28.28)$ & 19 (19.19) & $25(25.25)$ & $5(5.05)$ \\
\hline In our society, PLWA are abandoned by their friends ${ }^{a}$ & $15(15.63)$ & $16(16.67)$ & 19 (19.79) & $35(36.46)$ & $11(11.46)$ \\
\hline PLWA are losing their respect and status in the community ${ }^{a}$ & $13(13.40)$ & $19(19.59)$ & $11(11.34)$ & $39(40.21)$ & $15(15.46)$ \\
\hline Score of patient's social status: mean \pm SD & \multicolumn{5}{|c|}{$14.45 \pm 4.87(2.89 \pm 0.97)$} \\
\hline \multicolumn{6}{|l|}{ Social support } \\
\hline $\begin{array}{l}\text { Physicians, nurses and other health care providers should } \\
\text { accept and treat PLWA as those infected with other diseases }\end{array}$ & $5(5.21)$ & $6(6.25)$ & $6(6.25)$ & $38(39.58)$ & $41(42.71)$ \\
\hline $\begin{array}{l}\text { It should be allow PLWA to participate freely in all social } \\
\text { activities }^{b}\end{array}$ & $1(1.04)$ & $2(2.08)$ & $4(4.17)$ & $48(50.00)$ & $41(42.71)$ \\
\hline PLWA should be allowed to work with others ${ }^{b}$ & $1(1.03)$ & $3(3.09)$ & $5(5.15)$ & $49(50.52)$ & $39(40.21)$ \\
\hline $\begin{array}{l}\text { PLWA must be treated in the same way as other people in the } \\
\text { community }^{b}\end{array}$ & $5(5.10)$ & $2(2.04)$ & $5(5.10)$ & $42(42.86)$ & $44(44.90)$ \\
\hline Score of social support: mean \pm SD & \multicolumn{5}{|c|}{$16.84 \pm 2.85(4.21 \pm 0.71)$} \\
\hline \multicolumn{6}{|l|}{ Understanding the social about the disease } \\
\hline All PLWA are sinful ${ }^{a}$ & $57(60.00)$ & $18(18.95)$ & $12(12.63)$ & $6(6.32)$ & $2(2.11)$ \\
\hline PLWA are disgusting ${ }^{\mathrm{a}}$ & $60(62.50)$ & $23(23.96)$ & $7(7.29)$ & $5(5.21)$ & $1(1.04)$ \\
\hline $\begin{array}{l}\text { Only those who have high-risk sexual relationships are } \\
\text { infected with AIDS }\end{array}$ & $49(52.13)$ & $12(12.77)$ & $17(18.09)$ & $14(14.89)$ & $2(2.13)$ \\
\hline PLWA should be punished ${ }^{a}$ & $70(73.68)$ & $15(15.79)$ & $7(7.37)$ & $3(3.31)$ & No case \\
\hline HIV infection is penalty of wrong behaviors in the past ${ }^{\mathrm{a}}$ & $25(25.51)$ & $17(17.35)$ & $14(14.29)$ & $31(31.63)$ & $11(11.22)$ \\
\hline The best way to prevent AIDS is quarantine ${ }^{a}$ & $67(69.07)$ & $22(22.68)$ & $5(5.15)$ & $2(2.06)$ & $1(1.03)$ \\
\hline $\begin{array}{l}\text { Should not buy fruit and vegetable from HIV-infected } \\
\text { shopkeeper }\end{array}$ & $70(71.43)$ & $16(16.33)$ & $5(5.10)$ & $4(4.08)$ & $3(3.06)$ \\
\hline Score of understanding the social about the disease: mean \pm SD & \multicolumn{5}{|c|}{$29.28 \pm 4.38(4.18 \pm 0.62)$} \\
\hline \multicolumn{6}{|l|}{ Social harassment } \\
\hline PLWA are verbally abused ${ }^{a}$ & $17(17.53)$ & $13(13.40)$ & $25(25.77)$ & $36(37.11)$ & $6(6.19)$ \\
\hline PLWA are physical abused ${ }^{a}$ & $27(27.84)$ & $20(20.62)$ & $33(34.02)$ & $15(15.46)$ & $2(2.06)$ \\
\hline Score of social harassment: mean \pm SD & \multicolumn{5}{|c|}{$6.50 \pm 2.10(3.25 \pm 1.05)$} \\
\hline Total score of attitude: mean \pm SD & \multicolumn{5}{|c|}{$67.03 \pm 7.75(3.72 \pm 0.43)$} \\
\hline
\end{tabular}

*A for these questions strongly adverse is the correct answer. B for these questions, "strongly agree" is the correct answer PLWA - people living with AIDS

tude towards HIV infection can cause personal, familial, and social problems. Therefore, appropriate actions are needed to improve the attitude and to reduce the stigma regarding HIV infection. In present study, no significant difference was found between the attitude towards HIV infection of men and women. This finding is consistent with a study by Tavoosi et al., conducted in Iranian high-school student [2]. In a study of Baugher, females had a higher stigma scores in comparison with males [26]. However, a study by Hasan et al. indicated the opposite [15]. The results of our study revealed no significant difference regarding level of attitude toward HIV infection among different age groups. However, some studies have reported that older people have a higher attitude than younger people [23, 27]. Further, we found no significant relationship between attitude toward HIV infection and educational level. But, some studies conducted among PLHIV have shown that participants with higher education were more stigmatized than those with lower level of education $[23,28]$. Moreover, a study by Li et al. among general individuals in China reported that participants with lower education have a worse negative attitude [19]. In our study, the attitude towards HIV infection was the same among 


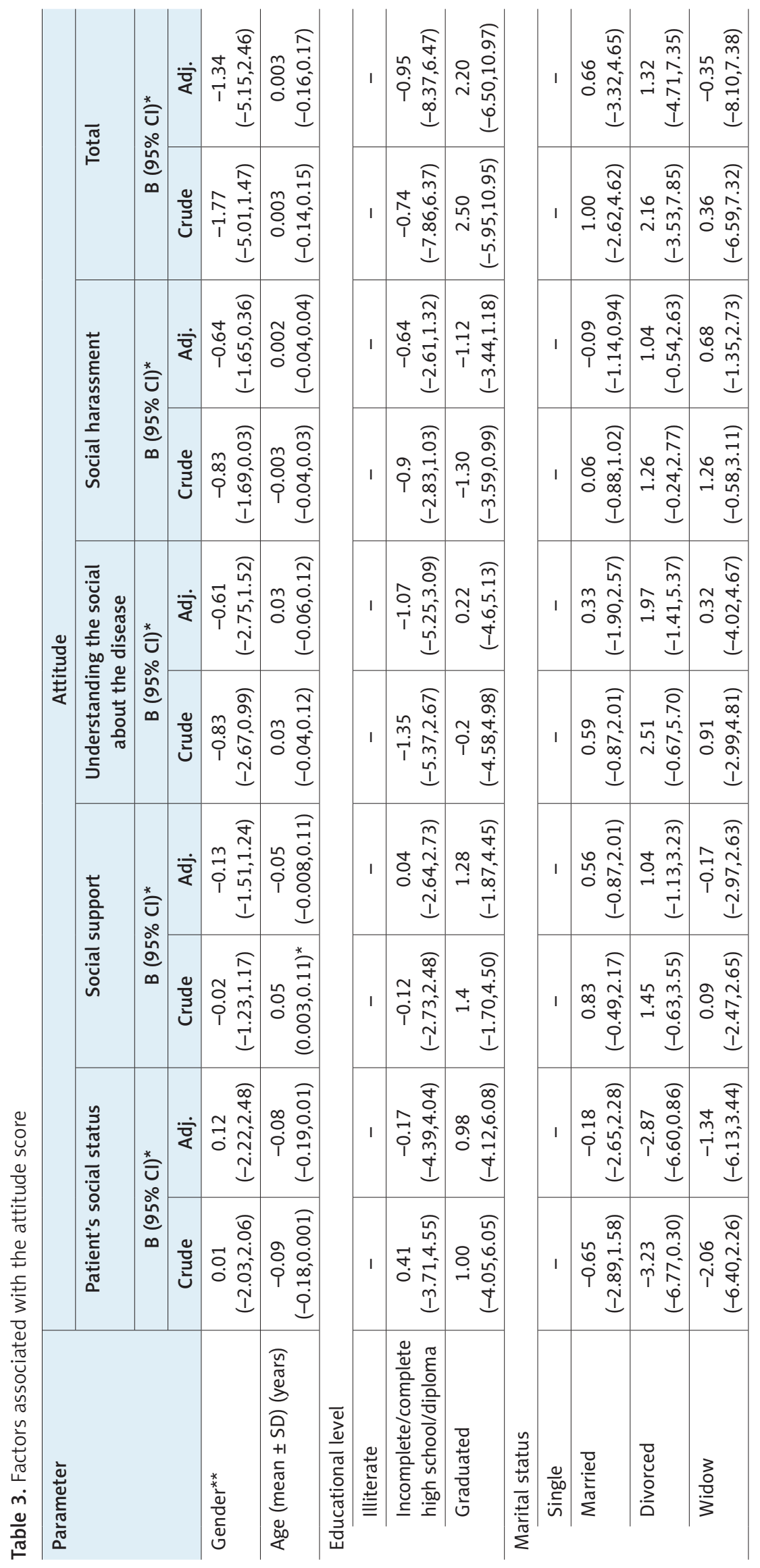

different marital groups and occupational groups. Therefore, the evaluated factors did not have a significant relationship with the attitude score. Different results of our study can be due to smaller sample size, when compared with other studies. Furthermore, differences in the results of present study with studies from other countries are caused by differences in the cultural backgrounds of participants.

Based on the outcomes, around half of participants felt that PLHIV would humiliate themselves and their families. A key reason was that Iran is a family-oriented society, and the Iranian culture is traditional and religious [4], in which people oppose behaviors that lead to AIDS, such as drug addiction, prostitution, adultery, alcoholism, and homosexuality. Such behaviors are perceived as abnormal and religious sins. The results of this study are consistent with a study by Karamouzian et al. [4]. Moreover, a study on women living with HIV in Iran shows that since HIV diagnosis, the participants experienced fear and shame [29]. Similar studies conducted in China and Bangladesh support this finding $[15,20]$.

The result of our study showed that, most participants (around 93\%) believed to allow PLHIV to joint freely in all social activities. Although a study on attitudes towards HIV/ AIDS among staff of an international organization in Bangladesh found that $41 \%$ of participants $(n=293)$ believed that people with AIDS should not be allowed to work [30].

Here, we found that $60 \%$ of the respondents were strongly declaring that PLHIV are sinful. Furthermore, another study from Iran reported that PLHIV often believed that HIV transmission and stigma were related to religious sins [31]. Dissimilarity of these results on this subject could be due to different questionnaires to evaluate this aspect.

Based on the reports, respondents believed that PLHIV should receive healthcare and treatment similar to other patients. According to the rights of patients with AIDS in domestic and international arenas, patients with AIDS in healthcare services should be considered similar to other patients [32]. Unfortunately, the reality is different. In a recent study from Iran, healthcare providers demonstrated such discriminatory behaviors to patients with AIDS more than towards other people in the community [4]. Moreover, a study by Rahmati et al. in Iran showed that PLHIV reported experiencing stigma and discrimination from healthcare 
providers [31]. These discriminatory behaviors and attitudes are not only in Iran, and have been reported in the literature from other countries $[17,33,34]$. Therefore, it seems that when PLHIV face discriminatory behaviors, they prefer not to reveal their HIV-positive status, subsequently expanding HIV prevalence. In this connection, some rules should be applied for PLHIV receiving healthcare and treatment like other patients.

This study has some limitations that must be considered. First, this was a cross-sectional study; therefore, the causal relationship in this study was not determined. Second, it was conducted only in Isfahan, and it is recommended to be carried out nationwide throughout the country. Finally, since the coverage of the medicine deputy system for registering the number of AIDS patients in Iran is poor [35], it seems that a large percentage of AIDS patients are not diagnosed or registered. In this study, all patients registered in Isfahan (including 99 people) were examined, but the sample size was small. If all not diagnosed patients were evaluated and studied, results of the study might differ.

To avoid or improve negative attitude towards PLHIV, we recommend national education program on HIV and its transmission routes for general population, healthcare workers, patients, and their families, so they can perceive HIV/AIDS as other diseases. Also, we suggest utilizing mass media as a quick and inclusive approach to community education. Education of youth and teenagers could improve society attitude in future generation, whereas regular and serious re-training programs are advised to improve the attitude of healthcare workers on PLHIV. In addition, managing and dealing with PLHIV should be included in educational curriculum of all medical sciences students. Furthermore, necessary educational programs should be provided to PLHIV and their families to release their fears and concerns. Most importantly, patients should receive supportive, psychological, non-ART interventions to erase the feeling of guilt and shame due to their status.

\section{Conclusions}

Our result indicated that attitude towards HIV infection were not satisfactory among PLHIV in Isfahan and HIV/ AIDS-related stigma can cause personal, familial, and social problems. Therefore, appropriate actions are needed to improve the attitude and reduce the stigma toward HIV infection.

\section{Acknowledgment}

The authors wish to express their gratitude to the Isfahan University of Medical Sciences for its support and all the participants who agreed to take part in the study. In addition, the authors would like to appreciate the HIV/STI Surveillance Research Center and WHO Collaborating Center for HIV surveillance, the Institute for Futures Studies in Health of Kerman University of Medical Sciences for advice on study implementation. We are also grateful to Dr. Marjan Meshkat for his help with data collection.

This research was supported by the Research Deputy of Isfahan University of Medical Sciences, with IRB code of 196015.

\section{Conflict of interest}

The authors declare no conflict of interest with respect to the research, authorship, and/or publication of this article.

\section{References}

1. Ghabili K, Shoja MM, Kamran P. The Iranian female high school students' attitude towards people with HIV/AIDS: a cross-sectional study. AIDS Res Ther 2008; 5: 15.

2. Tavoosi A, Zaferani A, Enzevaei A, Tajik P, Ahmadinezhad Z. Knowledge and attitude towards HIV/AIDS among Iranian students. BMC Public Health 2004; 4: 17.

3. Amiri FB, Doosti-Irani A, Sedaghat A, Fahimfar N, Mostafavi E. Knowledge, attitude, and practices regarding HIV and TB among homeless people in Tehran, Iran. Int J Health Policy Manag 2018; 7: 549-555.

4. Karamouzian M, Akbari M, Haghdoost AA, Setayesh H, Zolala F. "I am dead to them": HIV-related stigma experienced by people living with HIV in Kerman, Iran. J Assoc Nurses AIDS Care 2015; 26: $46-56$.

5. UNAIDS. Islamic Republic of Iran AIDS Progress Report 2018. Available at: http://www.unaids.org/en/dataanalysis/knowyourresponse/countryprogressreports/2018countries [In Persian].

6. Rasoolinajad M, Abedinia N, Noorbala AA, et al. Relationship among HIV-related stigma, mental health and quality of life for HIV-positive patients in Tehran. AIDS Behav 2018; 22: 3773-3782.

7. Zafarghandi MBS, Jadidi M, Khalili N. Iran's activities on prevention, treatment and harm reduction of drug abuse. Int J High Risk Behav Addict 2015; 4: e22863.

8. Ramezani A, Amirmoezi R, Volk JE, et al. HCV, HBV, and HIV seroprevalence, coinfections, and related behaviors among male injection drug users in Arak, Iran. AIDS Care 2014; 26: 1122-1126.

9. Selected Findings of the 2016 National Population and Housing Census. Available at: https://www.amar.org.ir/english/LatestReleases-Page/ID/5689/Selected-Findings-of-the-2016-NationalPopulation-and-Housing-Census (Accessed: 20.08.2017).

10. Abbasi-Shavazi MJ, Sadeghi R, Hosseini-Chavoshi M, Torabi F, Mahmoudiani S, Torkashvand M. Demographic and socio-economic status of youth in IR Iran. United Nations Population Fund, University of Tehran and Statistical Research and Training Center Google Scholar; 2013.

11. Census results of population and housing 2016 2017. Available at: www.mpo-es.ir/Dorsapax/userfiles/Sub1/g_sarshomari95.pdf.

12. Hedayati-Moghaddam M. Knowledge of and attitudes towards HIV/AIDS in Mashhad, Islamic Republic of Iran. East Mediterr Health J 2008; 14: 1321-1332.

13. Dahlui M, Azahar N, Bulgiba A, et al. HIV/AIDS related stigma and discrimination against PLWHA in Nigerian population. PLoS One 2015; 10: e0143749.

14. History of HIV and AIDS overview. Available at: https://www.avert. org/professionals/history-hiv-aids/overview (Accessed: 26.11.2018).

15. Hasan MT, Nath SR, Khan NS, Akram O, Gomes TM, Rashid SF. Internalized HIV/AIDS-related stigma in a sample of HIV-positive people in Bangladesh. J Health Popul Nutr 2012; 30: 22-30.

16. Jimenez JC, Puig M, Ramos JC, et al. Measuring HIV felt stigma: a culturally adapted scale targeting PLWHA in Puerto Rico. AIDS Care 2010; 22: 1314-1322. 
17. Makoae LN, Greeff M, Phetlhu RD, et al. Coping with HIV-related stigma in five African countries. J Assoc Nurses AIDS Care 2008; 19: $137-146$.

18. Ebrahimi-Kalan M, Rimaz S, AsghariJafarabadi M, et al. Validity and reliability of the Iranian version of the HIV/AIDS stigma instrument - PLWHA (HASI-P). Health Promot Perspect 2013; 3 : 194-205.

19. Li X, Yuan L, Li X, et al. Factors associated with stigma attitude towards people living with HIV among general individuals in Heilongiiang, Northeast China. BMC Infect Dis 2017; 17: 154.

20. Zhang YJ, Fan YG, Dai SY, et al. HIV/AIDS stigma among older PLWHA in south rural China. Int J Nurs Pract 2015; 21: 221-228.

21. Alwafi HA, Meer AM, Shabkah A, et al. Knowledge and attitudes toward HIV/AIDS among the general population of Jeddah, Saudi Arabia. J Infect Public Health 2018; 11: 80-84.

22. Tavakoli F. Assessment of social stigma associated with HIV/AIDS from the viewpoint of health care workers in Kerman in 1395. Kerman: Kerman University of Medical Sciences; 2018.

23. Li Z, Morano JP, Khoshnood K, Hsieh E, Sheng Y. HIV-related stigma among people living with HIV/AIDS in rural Central China. BMC Health Serv Res 2018; 18: 453.

24. Baugher AR, Beer L, Fagan JL, et al. Prevalence of internalized HIV-related stigma among HIV-infected adults in care, United States, 2011-2013. AIDS Behav 2017; 21: 2600-2608.

25. Haghdoost A, Pourkhandani A, Motaghipisheh S, Farhoudi B, Fahimifar N, Sadeghirad B. Knowledge and attitude concerning HIV/ AIDS among Iranian population: a systematic review and meta-analysis. Iran J Epidemiol 2011; 6: 8-20 [In Persian].

26. Brouard P, Wills C. A closer look: the internalization of stigma related to HIV. Washington, DC: United States Agency for International Development; 2006.

27. Shokoohi M, Karamouzian M, Mirzazadeh A, et al. HIV knowledge, attitudes, and practices of young people in Iran: findings of a national population-based survey in 2013. PLoS One 2016; 11: e0161849.

28. Nobre N, Pereira M, Roine RP, Sutinen J, Sintonen H. HIV-related self-stigma and health-related quality of life of people living with HIV in Finland. J Assoc Nurses AIDS Care 2018; 29: 254-265.

29. Oskouie F, Kashefi F, Rafii F, Gouya MM. Qualitative study of HIV related stigma and discrimination: what women say in Iran. Electron Physician 2017; 9: 4718-4724.

30. Islam MT, Mostafa G, Bhuiya AU, Hawkes S, De Francisco A. Knowledge on, and attitude toward, HIV/AIDS among staff of an international organization in Bangladesh. J Health Popul Nutr 2002; 20 : 271-278.

31. Rahmati-Najarkolaei F, Niknami S, Aminshokravi F, et al. Experiences of stigma in healthcare settings among adults living with HIV in the Islamic Republic of Iran. J Int AIDS Soc 2010; 13: 27.

32. Kord Z, Begjani J, Tamizi Z, Nejad EM. Nursing care of AIDS patients based on patient's rights in domestic and international arena: a review article. J Clin Excellence 2015; 4: 68-80 [In Persian].

33. Carr RL, Gramling LF. Stigma: a health barrier for women with HIV/AIDS. J Assoc Nurses AIDS Care 2004; 15: 30-39.

34. Gaudine A, Gien L, Thuan TT, Dung DV. Perspectives of HIV-related stigma in a community in Vietnam: a qualitative study. Int J Nurs Stud 2010; 47: 38-48.

35. Joulaei H, Lankarani KB, Kazerooni PA, Marzban M. Number of HIVinfected cases in Iran: true or just an iceberg. Indian J Sex Transm Dis AIDS 2017; 38: 157. 